\title{
Song Of The Open Road: Business Students Blog About Tacit Knowledge In Their Internships
}

Arlene O. DeWitt, Assumption College, USA

\begin{abstract}
Student interns produce professional blogs, using Web 2.0, to capture tacit knowledge concepts which are the experiential learning goals of internships in business education. This article discusses the pedagogical goals, methods and outcomes of this initiative. It also provides the theoretical underpinnings of the concept of tacit knowledge in viewing internships as a signature pedagogy in business education. It concludes with an application of this methodology to a strategic communication framework.
\end{abstract}

Keywords: business education pedagogy and research, internships, tacit knowledge, new media, blogs

\section{INTRODUCTION}

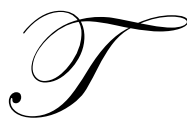

he open road - an electronic "net" highway- is where students flock to be participants and contributors of content in determining the course of their educational and professional journey. How do we harness this techno-human synergy in business education? Here's my approach: students create professional blogs - Web 2.0 products - to reflect, capture and communicate tacit knowledge in their internship experiences.

Student interns develop professional blog writing skills and produce a new media communication format blogs - for their two organizations: their college and their internship sponsors.

The theoretical underpinning of these internship blogs is the notion of tacit knowledge (Polanyi, 1983) - or the ability to think like a manager - which is an experiential learning goal of student internships in business education. This ability of business professionals to know - and to act and to do - in complex, multi-cultural, technologically-driven global business environments is the value-added resource which builds competitive advantage, effectiveness and efficiency in companies. It is a significant contributing factor to organizational success.

Thus, professional blog writing became the platform for a pedagogical writing initiative for Management, Marketing and Organizational Communication majors enrolled in my seminar course, Internship in Business, at Assumption College, Worcester, MA, this past 2009-2010 academic year.

Approximately 32 students blogged about their internship experiences on two landing pages of the college website: the major in Organizational Communication landing page (http://www1.assumption.edu/blogs/communications/) and the Internship landing page (http://www.assumption.edu/academics/internships.aspx).

\section{INTERNSHIP IN BUSINESS SEMINAR}

Students majoring in Organizational Communication at Assumption College are required to complete this 3-credit course, Internship in Business, which includes 120 on-site hours and a weekly seminar. Marketing, Management and International Business majors also enroll in this course. Interns are required to complete special 
assignments and projects at their internship sites which utilize their marketing, business communication and management knowledge bases and skills.

Interns are placed in the following areas: public affairs, public relations and internal communication; marketing and sales, institutional advancement, fundraising and development, online and hard copy publications, including newspapers, pop-culture magazines, industry-specific and practitioner journals.

Students attend a weekly seminar to discuss and to analyze macro and micro organizational behavior and management concepts and to share observations about their internships. Students assess their career competencies, organizational culture preferences, risk tolerances and supervisor/feedback requirements to determine their optimal career paths. They also conduct informational interviews with professionals in their career field or industry of interest. All students write an observation/reflection paper which analyzes and applies tactic knowledge concepts to their internship experiences.

\section{CONTENT OF BLOGS: TACIT KNOWLEDGE - THINKING LIKE A MANAGER}

These internship blogs proved to be the ideal new media format for students to reflect and to write about their tacit knowledge experiences. In fact, examples of tacit knowledge often became the "hook" and the "slice of life" piece of their blogs.

A student interning at the Worcester Business Journal (Wheeler, 2009) blogged: "I wrote an article about body language in the workplace... which we were learning about in my Interpersonal Communications class. I took this idea to my editor and wrote an article which included guidelines for body language in the workplace. In doing this, I learned that by taking the initiative and pushing for what you want, you can end up doing work that you enjoy and have a positive effect on the company in the process."

Blog writing provided the framework for the student who wrote this blog to reflect on, capture and appreciate the value of his initiative and his growth in this tacit knowledge experience.

It is interesting to note that in a recent survey by Sapp and Zhang (2010), internship sponsors rated the ability of most student interns to take initiative as low. Sapp and Zhang (2010) noted that "the lack of initiative can singularly affect students" ability to maximize the internship experience..." Thus, in this case, blog writing was also instrumental in the student being able to arrive at his own tacit knowledge learning goal of the value of taking initiative - or knowing and acting.

Students are asked to focus and write their blogs from the following guidelines:

- Describe lessons learned on-the-internship based on any of the following tacit knowledge concepts

(Pritchett, 1999):

Become a quick-change artist

Commit fully to your job

Speed up

Accept ambiguity and uncertainty

Behave like you're in business for yourself

Hold yourself accountable for outcomes

Add value

See yourself as a service center

Manage your morale

Practice kaizen

Be a fixer, not a finger-pointer

Alter your expectations

- $\quad$ Apply communication, marketing and/or management concepts learned in class

to your internship experience and/or tasks

- $\quad$ Give specific examples of internship tasks that you have found use your written and verbal communication skills and knowledge 


\section{THE CONCEPT OF TACTIC KNOWLEDGE IN SIGNATURE PEDAGOGIES AND BUSINESS EDUCATION}

The concept of tacit knowledge was revealed as a defining point of signature pedagogies in an ongoing 10year study conducted by the Carnegie Foundation for the Advancement of Teaching (2005) to understand how students are prepared for practice in the professional fields of law, engineering, the clergy, teaching, nursing and medicine. The foundation has concluded its study into the first three of these fields, and is pursuing its work in the latter fields.

Insight into the research approach of this Carnegie study comes from its president, Lee Shulman, who has devoted his lifetime to understanding the complexities, nuances and challenges of educating teachers. His approach is that of "looking through the lenses of parallel problems and challenges of preparing people for other professions because I find what professionals have to do - whether we call them teachers or lawyers, priests or nurses - is extraordinarily complex and endlessly fragmented (2005)." The concept of signature pedagogies is the resulting, synthesizing model for defining and understanding the core competencies required for pedagogy in professional fields.

The model of signature pedagogies is defined as: "a mode of teaching that has become inextricably identified with preparing people for a particular profession" (Shulman, 2005). While signature pedagogies are remarkably stable at any one point in time, they are always subject to change as conditions in the practice of the profession itself and in the institutions that provide service or care undergo larger societal change. Prototype examples include: the foundational and routine pedagogical practice of conducting clinical rounds in medical training, and the rules of engagement in accountable student dialogue in law school classrooms. (Shulman, 2005)

The three characteristics of signature pedagogies of the professions are: distinctiveness in the profession; pervasiveness in the curriculum incorporating powerful rules of engagement that form the thread of that it means to "to think like a doctor, lawyer, etc."; and as essential pedagogy to the entire profession as elements of both instruction and socialization. (Shulman, 2005)

In addition, Shulman (2005) tells us that professional education is a synthesis of three apprenticeships that focus on three domains: a cognitive domain, where students learn to think like a professional (think and act like a doctor, lawyer, etc); a practical domain, where students learn to perform as a professional; and a moral domain, where students learn to think and act in a responsible and ethical manner that integrates across all three domains.

In conclusion, Shulman (2005) explicitly emphasizes that signature pedagogies are designed to transform knowledge attained to "knowledge-in-use, and create the basis of new kinds of understanding that can only be realized experientially and reflectively".

The "knowledge-in-use" application to business education is the theoretical underpinning of student internships, which are our signature pedagogy in business education, that enable our students to acquire the valueadded, tacit knowledge of learning to think like a manager.

\section{THE SIGNIFICANCE OF ACTION AND ITS APPLICATION TO BUSINESS EDUCATION}

The significance of action - or the experiential element - is the definitive criteria of signature pedagogies that connects to internships in business education. Shulman refers to action as the universal characteristic of all signature pedagogies. In fact, he collectively terms signature pedagogies: "pedagogies of action".

A professional is not someone for whom understanding is sufficient. Understanding is necessary, yes, but not sufficient. A professional has to be prepared to act, to perform, to practice whether they have enough information or not...Action is equally important, maybe more important than understanding. (Shulman, 2005)

Economist Frederick Hayek refers to this type of knowledge as a stock of expertise within an organization which is not written down or even firmly expressed, but may nevertheless be essential to the organization's effective 
operation (Barney, 1991). The theoretical resource-based view of the firm or organization (Barney, 1991) also confirms the value of an action orientation in understanding knowledge.

Polanyi (1962) explains that tacit knowledge is knowledge which cannot be articulated, and which is deeply embedded in the knower's cumulative perceptions and experiences. He describes this implicit knowledge as "we can know more than we can tell" (Polanyi, 1983). He argued that "skillful action always involves a tacit component, even if some aspects of the action draw upon codified (explicit) knowledge".

Brown and Duguid (1991) conclude that "novices acquire tacit knowledge through active participation with those who have mastered a skill". "Absent the requisite tacit knowledge, codified knowledge cannot be exploited" (Miller, Zhao, Calantone, 2006) or turned into the notion of thinking and acting like a manager.

\section{PEDAGOGICAL OUTCOMES}

I start each weekly seminar with the electronic projection of these internship blogs to:

- $\quad$ build a community of interns through sharing of experiences

- $\quad$ stimulate a nuanced critique of professional blog writing

- $\quad$ initiate tacit knowledge content discussion in the seminar

- $\quad$ reinforce the link between tacit knowledge and career success

- $\quad$ emphasize the value of tacit knowledge to the success of the organization

Students also include their internship blogs in their career portfolios as examples of professional writing in the new media forum.

\section{BLOG OUTCOMES FOR THE COLLEGE AND INTERNSHIP SPONSORS}

1. As a result of these internship blogs recording so many "hits' on the Assumption College website, the Admissions Office featured these student intern blogs in their promotional marketing to prospective students. Mario J. Silva-Rosi, Director of Admissions, writes:

We, in Admissions, feel that in order for our prospective students to get a better understanding of what life is like at Assumption, the blogs have become a key element in our ability to share content - and are at the same time, a tool for students to share their opinions in an appealing, new technological way. It is crucial to have the prospective coming directly from our students.

The integration of blogs on our website has allowed for a great sense of awareness, not only for current students involved in internships, but also for prospective students, with the most accurate picture as to what actually happens at those sites. This certainly gives a better framework for understanding the relationship between - classroom and work place - experience.

Thus, students witnessed that their development of blogs and participation in the blogosphere created an important tool for the Admissions Office to "proactively glean insights about constituency attitudes, sentiments, and reactions... as an unprecedented and ideal survey group" (Argenti, 2009).

2. These internship blogs served to raise awareness of and to inform our internal constituencies at the college about our major in Organizational Communication and the skills and career potential of our graduates.

3. Internship sponsors viewed these blogs as positive vehicles for community-building public relations and committed to sponsoring additional interns. 


\section{BLOG FORMAT}

Name

Hometown, State

Major

Internship Sponsor

Primary Responsibilities: no more than 50 words

Blog Entry: 100 words minimum, 250 words maximum

Photos: Students supplied digital photographs of themselves at their internship sites. They complete signed release forms from their organizations.

\section{BLOG PROCESS}

Students sign up at the beginning of the semester for their blog dates(s).

At the end of each weekly seminar, I conduct 1-1 tutorials with each student to revise/edit their blogs. The emphasis is on content/the hook, clarity, conciseness and the use of action verbs. I stress that specific examples are critical to applying tacit knowledge concepts.

Students then electronically submit their revised/edited blogs and digital pictures to me. I review the final blogs and then electronically submit them to our Public Affairs Office which posts them on the college website.

\section{CONCLUSION}

Applying Argenti's (2009) strategic communication framework (Figure 1) to the internship blogging initiative reveals why blogging is a valuable experiential methodology which empowers students with tacit knowledge.

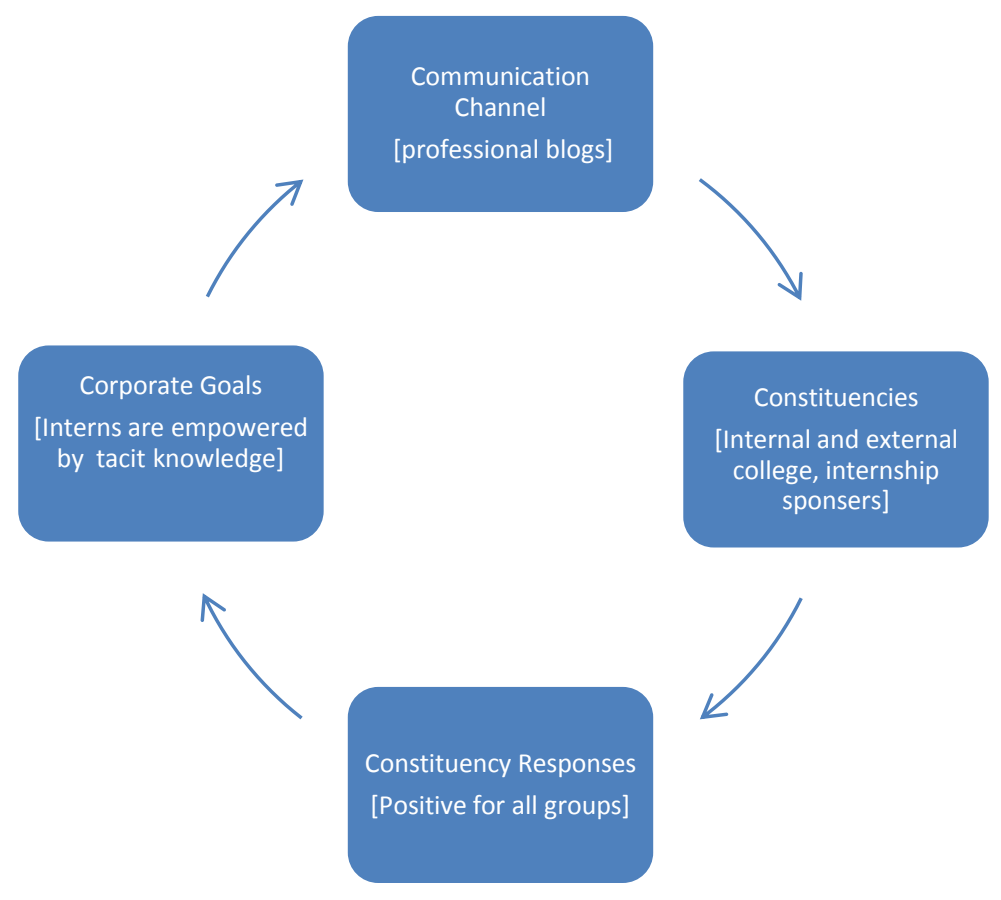

Figure 1: Strategic Communication Framework

Argenti, P. (2009). Corporate Communication, Fourth Edition. New York: McGraw-Hill Irwin, 35. 
I encourage you to view the internship blogs with the hope that you will find this methodology useful in your internship programs.

\section{AUTHOR INFORMATION}

Arlene O. DeWitt is an Assistant Professor of Organizational Communication and Marketing at Assumption College, Worcester, MA, where she teaches Communication Theory, Strategic Managerial Communication and other marketing and management courses. She developed the Internship in Business seminar required for Organizational Communication majors. She also teaches the Technical and Professional Communication Seminar in the M.B.A. Program at Assumption. She has professional writing experience in public relations, journalism and strategic business communication.

\section{REFERENCES}

1. Argenti, P. (2009). Corporate Communication, New York: McGraw-Hill Irwin, 171, 40.

2. Barney, J. (1991). Firm resources and sustained competitive advantage. Journal of Management, 17(1): 99-120.

3. Brown, J.S. \& Duguid, P. (1991). Organizational learning and communities-of-practice: Toward a unified view of working, learning and innovation. Organizational Science, 2:40-57.

4. Miller, Kent D., Zhao, Meng \& Calantone, Roger J. "Adding Interpersonal Learning and Tacit Knowledge to March's Exploration-Exploitation Model.” The Academy of Management Journal 49.4 (2006): 719.

5. Polanyi, M. (1962). Personal Knowledge. Chicago, IL: The University of Chicago Press, 121.

6. $\quad$ Polanyi, Michael. (1983). The Tacit Dimension. Gloucester, MA: Peter Smith, 4.

7. Pritchett, P. (1999). The Employee Handbook of New Work Habits for a Radically Changing World, Dallas, TX: Pritchett Rummler-Brache Group, 15.

8. Sapp, D. \& Zhang, Q. (2010) Trends in Industry Supervisors' Feedback on Business Communication Internships. Business Communication Quarterly, 72, 280.

9. Shulman, Lee. "The Signature Pedagogies of the Professions of Law, Medicine, Engineering, and the Clergy: Potential Lessons for the Educations of Teachers." National Research Council's Center for Education. Irvine. 6-8 February 2005.

10. “Tacit knowledge and Implicit Learning.” Learning and Teaching. 2007. <http://www.learningandteaching.info/learning/tacit.htm>.

11. Wheeler, D. (Nov 9, 2009) Retrieved July 1, 2010 from http://www1.assumption.edu/blogs/communications/?paged=3 